\title{
Nanoemulgel, an Innovative Carrier for Diflunisal Topical Delivery with Profound Anti-Inflammatory Effect: in vitro and in vivo Evaluation
}

This article was published in the following Dove Press journal: International Journal of Nanomedicine

\author{
Mehreen Bashir' \\ Junaid Ahmad' \\ Muhammad Asif ${ }^{2}$ \\ Salah-Ud-Din Khan ${ }^{3}$ \\ Muhammad Irfan' \\ Asim Y Ibrahim ${ }^{4}$ \\ Sajid Asghar' \\ Ikram Ullah Khan (iD) \\ Muhammad Shahid Iqbal ${ }^{5}$ \\ Abdul Haseeb ${ }^{6}$ \\ Syed Haroon Khalid (D) \\ Mohammed AS Abourehab ${ }^{7,8}$ \\ 'Department of Pharmaceutics, Faculty of \\ Pharmaceutical Sciences, Government \\ College University, Faisalabad, 38000 , \\ Pakistan; ${ }^{2}$ Department of Pharmacology, \\ Faculty of Pharmacy, The Islamia University \\ of Bahawalpur, Bahawalpur, Pakistan; \\ ${ }^{3}$ Department of Biochemistry, College of \\ Medicine, Imam Mohammad Ibn Saud Islamic \\ University, Riyadh, Saudi Arabia; ${ }^{4}$ Faculty of \\ Pharmacy, Omdurman Islamic University, \\ Omdurman, Sudan; ${ }^{5}$ Department of Clinical \\ Pharmacy, College of Pharmacy, Prince \\ Sattam Bin Abdulaziz University, Alkharj, \\ Saudi Arabia; ${ }^{6}$ Department of Clinical \\ Pharmacy, College of Pharmacy, Umm Al- \\ Qura University, Makkah, 21955, Saudi \\ Arabia; ${ }^{7}$ Department of Pharmaceutics, \\ Faculty of Pharmacy, Umm Al-Qura \\ University, Makkah, Saudi Arabia; \\ ${ }^{8}$ Department of Pharmaceutics and \\ Industrial Pharmacy, Faculty of Pharmacy, \\ Minia University, Minia, Egypt
}

Correspondence: Syed Haroon Khalid Department of Pharmaceutics, Faculty of Pharmaceutical Sciences, Government College University, Faisalabad, 38000, Pakistan

Tel +92-31667522223

Email syedharoonkhalid@gcuf.edu.pk
Purpose: Rheumatoid arthritis is an autoimmune disorder that directly affects joints. However, other body organs including heart, eyes, skin, blood vessels and lungs may also be affected. The purpose of this study was to design and evaluate a nanoemulgel formulation of diflunisal (DIF) and solubility enhanced diflunisal (DIF-IC) for enhanced topical antiinflammatory activity.

Methodology: Nanoemulsion formulations of both DIF and DIF-IC were prepared and incorporated in three different gelling agents, namely carboxymethylcellulose sodium (CMC$\mathrm{Na}$ ), sodium alginate (Na-ALG) and xanthan gum (XG). All the formulations were evaluated in term of particle size, $\mathrm{pH}$, conductivity, viscosity, zeta potential and in vitro drug release. The formulation 2 (NE2) of both DIF and DIF-IC which expressed optimum release and satisfactory physicochemical properties was incorporated with gelling agents to produce final nanoemulgel formulations. The optimized nanoemulgel formulation was subjected to three different in vivo anti-inflammatory models including carrageenan-induced paw edema model, histamine-induced paw edema model and formalin-induced paw edema model.

Results: DIF-IC-loaded nanoemulgel formulations yielded significantly enhanced in vitro skin permeation than DIF-loaded nanoemulgel. The nanoemulgel formulation of DIF-IC formulated with XG produced improved in vivo anti-inflammatory activity.

Conclusion: It was recommended that DIF-IC-based nanoemulgel formulation prepared with XG could be a better option for effective topical treatment of inflammatory conditions. Keywords: diflunisal, nanoemulsion, pseudoternary phase diagram, in vitro skin permeation, anti-inflammatory activity, improved efficacy

\section{Introduction}

Rheumatic diseases, the leading cause of disability and locomotor dysfunction in the human (adult) population, are generally categorized under arthritic disorders. ${ }^{1}$ Osteoarthritis and rheumatoid arthritis (RA) are considered as the most established manifestations of these articular problems. The most recurrent symptom associated with RA (an autoimmune disorder) is joint pain, leading to decreased motility, sleep disturbance, physical disability, increased health-related costs, and ultimately to lifelong inflammatory complications. ${ }^{2,3}$ Several pro-inflammatory cytokines including TNF- $\alpha$, IL- $1 \beta$ and IL- 6 are activated in RA. ${ }^{4}$ The effective treatment of active RA relies on the biological targeting of these cytokines with a suitable drug regimen.

Topical drug delivery involves application of medication directly to the skin surface. $^{5}$ It offers many advantages such as avoidance of first pass effects, frequent 
dosing, no gastric degradation, ease of application and termination. The particle size of the active drug moiety is decisive for the penetration of drug molecules through underlying skin barriers. Vehicle composition and the physicochemical properties of drugs are the prime factors that govern drug release and the therapeutic efficacy of the dermal formulations. ${ }^{6}$

Traditional topical vehicles including lotions, ointments, patches and creams are associated with many drawbacks such as limited drug loading efficiency and poor penetrability. Furthermore, they can be sticky with less spreading coefficient, so require rubbing for application leading to patient discomfort. Stability is also a prime issue with such formulations. Formulation scientists have introduced the concept of transparent gels to address issues related to conventional topical dosage forms, but an inability to deliver lipophilic drugs is a major drawback associated with gels. $^{7}$

It is evident from the literature that topical nanosized formulations could promote drug delivery by inducing temporary disruption in a highly organized lipid bilayer structure. A nanoemulsion is considered a transparent, thermodynamically stable and optically isotropic colloidal system having droplet size of 20-200 nm. ${ }^{8}$ Nanoemulsions are composed of oils and surfactants usually in association with co-surfactants. ${ }^{9}$ Despite many benefits, low viscosity and spreadability are the main drawbacks of topical nanoemulsion formulations. ${ }^{10}$ Based on this status quo, researchers converted nanoemulsion, either water in oil (w/o) or oil in water $(\mathrm{o} / \mathrm{w})$ into nanoemulgel by mixing with gelling agents for effective topical drug delivery. ${ }^{11}$ Their acceptability is further supported by their properties including non-staining, thixotropy, emollient, non-greasy, good spreadability, pleasant appearance and ease of removal. ${ }^{12}$

Anti-inflammatory drugs/analgesics can be suitable therapies for the mitigation of inflammation and joint pain, but their persistent use is associated with several deleterious side effects, patient non-compliance and low efficacy. ${ }^{13}$ Non-steroidal anti-inflammatory drugs (NSAIDs) are widely used for the long-term treatment of chronic rheumatic diseases.

DIF, a salicylic acid derivative with longer duration of action is administered to patients over prolonged periods of time, so effective measures should be adopted to minimize associated side effects and to prevent damage to internal organs. ${ }^{14}$ Topical administration of DIF could be a promising method to address the side effects related to oral administration. A major problem associated with topical delivery of DIF is its poor aqueous solubility.

In our previous publication, we formulated ternary complexes of DIF by using different hydrophilic polymers, in order to optimize drug delivery. The highest solubility was reported with a ternary complex of DIF with HP $\beta C D$ and PXM-188. ${ }^{15}$ In this article we focus on enhancing solubility and anti-inflammatory activity of DIF by incorporating it in a nanoemulgel using different gelling agents (Na-ALG, CMC-Na and XG). Previously, Sallam et al. ${ }^{14}$ developed a microemulsion-based gel of DIF (5\%). But according to the literature and preclinical investigations, the minimum effective concentration (MEC) of DIF for topical/localized effect may be only $0.04 \% \mathrm{w} / \mathrm{w}$ proven by quality by design (Qbd) studies. ${ }^{16}$ The unique feature of our present study is that we designed a nanoemulgel formulation that will produce a therapeutic effect at low drug concentration $(1 \%)$ in comparison with other reported studies. We are going to introduce a new concept of incorporation of solubility enhanced DIF (DIF/HP $\beta C D$ / PXM-188) into a nanoemulsion followed by mixing with different gelling bases to develop a nanoemulgel formulation and evaluate its solubility, dissolution and anti-inflammatory activity against the nanoemulgel prepared with pure DIF and a marketed brand of diclofenac diethylamine $\left(\right.$ Voltral $\left.^{\circledR}\right)$.

\section{Materials and Methods Materials}

DIF was supplied by AK Scientific (US). Sunflower oil, lavender oil, sandalwood oil, eucalyptus oil and rosemary oil were obtained from Go Natural, Pakistan. Olive oil was acquired from Jiaxing, Sunlong Industrial and Trading Co. Ltd, China. Glycerine, propylene glycol, Tween 80, Tween 40, Tween 20, Span 20, Span 80, Transcutol-P and CMC$\mathrm{Na}$ were purchased from Sigma-Aldrich, USA. Na-ALG, PEG 400 and propanol were purchased from Daejung, Korea. Analytical grade chemicals/reagents were used in the study.

\section{Solubility Studies}

Various oils (sunflower oil, lavender oil, sandalwood oil, eucalyptus oil, rosemary oil and olive oil), surfactants (Tween-80, Tween-40, Tween-20, Span-80 and Span-20) and co-surfactants (glycerine, propylene glycol, propanol, PEG-400, transcutol-P) were used for solubility determination of DIF. The solubility of DIF in different surfactant/ 
co-surfactant $(\mathrm{S} / \mathrm{Co}-\mathrm{S})$ ratios including $1: 1,1: 2$ and 2:1 was also determined to specify the $\mathrm{S} / \mathrm{Co}-\mathrm{S}$ mixture ratio for the construction of a pseudo-ternary phase diagram. Drug was added in excess in $2 \mathrm{~mL}$ of each excipient followed by vortex mixing for about $2 \mathrm{~min}$ and settled in a reciprocating shaking water bath at $37^{\circ} \mathrm{C}$ and $100 \mathrm{rpm}$ for the next 72 hours. The resultant mixture was then subjected to centrifugation for $5 \mathrm{~min}$ at $3000 \mathrm{rpm}$. The undissolved fraction of drug was removed by 0.45 um membrane filters. The clear supernatant was then diluted suitably with methanol and analyzed spectrophotometrically at $251.5 \mathrm{~nm}$ wavelength using methanol as blank.

\section{Construction of the Pseudo-Ternary Phase Diagram}

Water titration method was adopted to develop a pseudoternary phase diagram to draw the nanoemulsion zone and define concentration ratios of the individual components. ${ }^{17}$ In different glass tubes, oil was mixed thoroughly with $\mathrm{S} / \mathrm{Co}-\mathrm{S}$ at different weight ratios of $0.5,9.5,1.0: 9.0,1.5: 8.5,2.0: 8.0$, 2.5: 8.5, 3.0: 7.0, 3.5: 6.5, 4.0: 6.0, 4.5: 5.5, 5.0: 5.0, 6.0: 4.0, 7.0: 3.0, 8.0: 2.0 and 9.0: 1.0. Aqueous phase was then added drop-wise into each tube (at $26 \pm 2^{\circ} \mathrm{C}$ ) followed by $2 \mathrm{~min}$ vortex mixing and allowed to equilibrate after light magnetic stirring for $20 \mathrm{~min}$. After equilibrium establishment, the mixtures were described in term of flowability and phase clarity. The clear emulsion with good flowability was declared as nanoemulsion. ${ }^{18}$ Chemix (cxse 700) was used to construct the ternary diagram.

\section{Preparation of Nanoemulsion Formulae}

Suitable weight ratios for oil and $\mathrm{S} / \mathrm{Co}-\mathrm{S}$ were selected from the pseudo-ternary phase diagram and different formulae were designed on the basis of the nanoemulsion (NE) region in the diagram. $\mathrm{O} / \mathrm{w}$ nanoemulsion was expected to form by these weight ratios due to comparatively lower oil ratio than water. The physical state and clarity (transparency) was observed in these NE systems.

\section{Preparation of Drug-Loaded Nanoemulsion Formulae and Nanoemulsion-Based Gel}

DIF and solubility enhanced DIF (DIF-IC) were added to the $\mathrm{S} / \mathrm{Co}-\mathrm{S}$ mixture and mixed thoroughly by vortex mixer for $2 \mathrm{~min}$ followed by addition of oil with continuous mixing. Finally a specified weight of aqueous phase was added drop-wise to acquire an homogeneous nanoemulsion. The effect of drug loading was determined in term of physical state and transparency of nanoemulsions.

The optimized nanoemulsion formulations of both DIF and DIF-IC were gelled using three different gelling agents, viz. CMC-Na, XG and Na-ALG. For the preparation of the gel base of $\mathrm{XG}, 3 \%$ of $\mathrm{XG}$ was added in purified water and stirred continuously to form an homogeneous base, followed by $\mathrm{pH}$ adjustment with triethanolamine. ${ }^{19}$ The gel bases of the other two gelling agents were made by dissolving $3 \%$ of both $\mathrm{CMC}-\mathrm{Na}$ and $\mathrm{Na}-\mathrm{ALG}$ in defined volumes of water by stirring for a period of 2 hand finally adjusting their $\mathrm{pH}^{20}$ The three different gel bases were mixed with the optimized NE formulae separately in $1: 1$ by magnetic stirring at 250 rpm for about 15 min until smooth and viscous nanoemulsion-based gels were formed.

\section{Characterization of Nanoemulsion and Nanoemulgel Formulations}

Malvern Zetasizer Nano ZS90, UK was used to measure particle size and polydispersity. The measurements were performed in triplicate at $25^{\circ} \mathrm{C}$ and fixed angle $\left(90^{\circ}\right)$. The test samples were poured in sample cells after suitable dilution. Polydispersity index values were used to ensure particle diameter uniformity. Malvern Zetasizer Nano ZS (Malvern Instruments, Ltd, UK) Series ZEN3600 with electrophoretic light scattering along with a particle size analyzer was used to measure the zeta potential of NE formulae by applying electric field of one volt. For the measurement of zeta potential, the samples were diluted appropriately with prefiltered double distilled water and readings were taken in triplicate. Digital $\mathrm{pH}$ meter $(\mathrm{pH} 7110$ Xylem Analytics Germany $\mathrm{GmbH}$ ) was used to determine $\mathrm{pH}$ of both blank and drug-loaded NE formulations and taken in triplicate. The type of NE (either o/w or w/o) was verified by performing a conductivity test. For this purpose, the electrode of digital conductometer (HANNA ${ }^{\circledR}$ Instruments, HI9811-5, Romania) was dipped in the NE formulations and the readings noted in triplicate. Viscosity of NE formulae was determined by Brookfield viscometer (DV-II+ Pro) using spindle 63 with spindle speed of $100 \mathrm{rpm}$. The formed emulgel formulations were subjected to tests similar to those performed for $\mathrm{NE}(\mathrm{pH}$, viscosity and conductivity).

\section{In vitro Skin Permeation Study}

All animal handling procedures were performed according to the Guide for the Care and Use of Laboratory Animals 
of the National Institutes of Health and followed the guidelines of the Animal Welfare Act. All protocols were also reviewed by the Institutional Animal Care and Use Committee Government College University Faisalabad (Faisalabad, Pakistan) prior to granting approval for the study (GCUF/ERC/2043). Male albino rat skin (shaved dorsal skin) was used to perform an in vitro skin permeation study. The rats were sacrificed and dorsal hair was removed followed by surgical removal of skin. The excised skin was then stored at $-20^{\circ} \mathrm{C}$ after washing with phosphate buffer solution. For the skin permeation study, Franz diffusion cell $(9 \mathrm{~mL})$ with effective diffusion area of $1.76 \mathrm{~cm}^{2}$ was used. Fat and other associated subcutaneous tissues were removed by scalpel from the dermal edge and the processed patch was placed between receptor and donor compartments of a cell with dermal layer towards receptor chamber and the stratum corneum (horny layer) was facing the donor compartment.

One $\mathrm{mL}$ of each test formulation was placed on the epidermal skin side. The PBS ( $\mathrm{pH} \mathrm{7.4)} \mathrm{was} \mathrm{filled} \mathrm{in} \mathrm{the}$ receptor chamber. After placing Franz diffusion cell on magnetic stirrer, the magnetic bead was rotated at fixed speed of $300 \mathrm{rpm}$ at temperature $37 \pm 0.5^{\circ} \mathrm{C} .{ }^{17}$ Samples were taken at predetermined time intervals for the next $24 \mathrm{~h}$ and analyzed spectrophotometrically at $251.5 \mathrm{~nm}$ wavelength after suitable dilution. Equal volume of fresh dissolution medium was replenished after each sampling. The mean cumulative quantity of permeated drug from the formulations through skin (per $\mathrm{cm}^{2}$ ) was plotted against time to obtain DIF permeation profile. For each formulation, permeability coefficient (Kp) and flux $(\mathrm{J})$ were calculated separately.

By using linear regression analysis, the cumulative quantity of DIF that permeated through rat epidermal membrane per $\mathrm{cm}^{2}$ at steady state was plotted against time and the slope of resultant plot was used to calculate flux $\left(\mu \mathrm{g} / \mathrm{cm}^{2} . \mathrm{h}\right)$. The permeability coefficient $(\mathrm{Kp})$ was calculated using the following equation:

$$
\mathrm{Kp}=\mathrm{J} / \mathrm{C}
$$

Where $\mathrm{J}$ indicates the flux and $\mathrm{C}$ denotes the DIF concentration in the donor chamber. ${ }^{21}$

The in vitro skin permeation study for nanoemulgel formulations was performed under the same conditions as used for nanoemulsion formulations.

\section{In vivo Anti-Inflammatory Study}

The rats were divided into five groups $(n=5)$ for evaluating anti-inflammatory effect as:
Group 1: (Control): untreated inflammation induced group.

Group 2: (Standard): received diclofenac diethylamine emulgel.

Group 3: (treated with DIF-loaded nanoemulgel).

Group 4: (treated with DIF-IC-loaded nanoemulgel).

Group 5: (Healthy rats).

\section{Acute Inflammatory Models}

To minimize the number of animals used in the experiments, the same animals were reused after executing one acute inflammatory model. Before use in the next model, a washout period of 2 weeks was given to experimental rats and only those animals having no signs of inflammation/necrosis or any physical disability were reused.

\section{Carrageenan and Histamine-Induced Paw Edema Model}

$1 \%$ carrageenan $(0.1 \mathrm{~mL})$ and histamine were administered to each rat of every group through subcutaneous administration of right hind paw in the sub-plantar surface. The test formulations and standard were applied half an hour before the administration of carrageenan/histamine. The paw volume was monitored at regular time intervals i.e. $0,1,2,3$ and 4 husing a digital Vernier caliper. Percent inhibition of paw volume was determined through equation 2 and represented as mean $\pm \mathrm{SD}^{22}$

$$
\begin{aligned}
\text { \%inhibition }= & \text { increase in paw volume }(\text { control }) \\
& - \text { increase in paw volume }(\text { test })
\end{aligned} \times 100
$$

\section{Chronic Inflammatory Models \\ Formaldehyde-Induced Arthritis}

The rats were pretreated with test formulations and standard $30 \mathrm{~min}$ before the formalin administration. $0.1 \mathrm{~mL}$ of formaldehyde (2\%) was injected in the sub-plantar region of left hind paw of all rats on days 1 and 3 of the study for edema induction. Digital Vernier caliper was used for paw volume measurement for 13 consecutive days. Percentage inhibition was calculated using equation 2. Results are presented as mean \pm SD of percentage inhibition of paw edema. ${ }^{23}$

\section{Statistical Analysis}

$\operatorname{SPSS}^{\circledR}$ (version 16, USA) was used for statistical analysis and results were expressed in the form of mean \pm standard deviation (SD). 


\section{Results}

\section{Solubility Study}

The solubility of DIF was determined in different oils, surfactants and co-surfactants as shown in Table 1. For the development of stable NE, the critical factor is the solubilizing capacity of oil because it demonstrates drug-loading efficiency indirectly. ${ }^{24}$ The highest solubility was observed with eucalyptus oil $(130.02 \mathrm{mg} / \mathrm{mL})$ among all the oils, as shown in Table 2, therefore it was selected for further investigation.

Table I The Solubility Values of DIF in Various Oils, Surfactants, Co-Surfactants and Surfactant-Co-Surfactant Mixture. Mean \pm $\mathrm{SD}, \mathrm{N}=3$

\begin{tabular}{|l|l|}
\hline Components & Solubility $(\mathbf{m g} / \mathbf{m L})$ \\
\hline Oils & \\
Sunflower oil & $6.39 \pm 0.0006$ \\
Lavender oil & $78.64 \pm 0.0006$ \\
Sandalwood oil & $88.13 \pm 0.006$ \\
Eucalyptus oil & $130.02 \pm 0.02$ \\
Rosemary oil & $96.40 \pm 0.05$ \\
Olive oil & $7.45 \pm 0.001$ \\
\hline Surfactants & \\
Tween 80 & $64.24 \pm 0.002$ \\
Tween 40 & $57.45 \pm 0.02$ \\
Tween 20 & $42.37 \pm 0.03$ \\
Span 20 & $7.38 \pm 0.006$ \\
Span 80 & $7.05 \pm 0.01$ \\
\hline Co-surfactants & \\
Glycerine & $4.29 \pm 0.0006$ \\
Propylene glycol & $61.86 \pm 0.0006$ \\
Propanol & $215.25 \pm 0.01$ \\
PEG 400 & $203.39 \pm 0.01$ \\
Transcutol-P & $393.13 \pm 0.06$ \\
\hline Surfactant mixture & \\
Tween 80 + Transcutol-P (I:I) & $366.01 \pm 0.01$ \\
Tween 80 + Transcutol-P (I:2) & $401.33 \pm 0.58$ \\
Tween 80 + Transcutol-P (2:I) & $271.67 \pm 0.58$ \\
\hline
\end{tabular}

Table 2 The Blank NE Formulations Containing Various Compositions of Eucalyptus Oil and Tween 80/Transcutol-P (I:2) Selected from Pseudo-Ternary Phase Diagram

\begin{tabular}{|l|l|l|l|}
\hline $\begin{array}{l}\text { Matrix } \\
\text { Code }\end{array}$ & $\begin{array}{l}\text { Eucalyptus } \\
\text { Oil (\%w/w) }\end{array}$ & $\begin{array}{l}\text { S/Co-S (Tween-80/ } \\
\text { Transcutol-P) }(\% w / w)\end{array}$ & $\begin{array}{l}\text { Water } \\
(\% \mathbf{w} / \mathbf{w})\end{array}$ \\
\hline NE I & 05 & 35 & 60 \\
NE 2 & 10 & 40 & 50 \\
NE 3 & 10 & 45 & 45 \\
NE 4 & 15 & 45 & 40 \\
NE 5 & 20 & 50 & 30 \\
\hline
\end{tabular}

For NE formulation, non-ionic surfactants are mostly preferred than their ionic complement due to bioactivity and toxicity related issues. ${ }^{25}$ Generally, surfactants with hydrophilic characters are considered as bioactively safe excipients. ${ }^{26}$ Tween $80(64.24 \mathrm{mg} / \mathrm{mL})$ expressed the highest solubility among all surfactants. Being hydrophilic (HLB 14.5) it was quite suitable for $\mathrm{o} / \mathrm{w}$ NE formulation. Among the co-surfactants, Transcutol-P was selected due to its higher solubilization capacity $(393.13 \mathrm{mg} / \mathrm{mL})$. It also acts as an effective penetration enhancer. ${ }^{27}$ A statistically significant difference $(p<0.05)$ is present in DIF solubility in oils, surfactants and cosurfactants.

\section{Development of a Pseudoternary Diagram}

A pseudoternary phase diagram was designed for the optimization of concentration for oil, surfactant and co-surfactant and also to identify the NE zone in the absence of DIF. The ratio of 1:2 was selected for the construction of the ternary diagram. The NE region is indicated by the shaded area (Figure 1).

\section{Selection of Formulae}

From the pseudo-ternary phase diagram, many formulae can be designed from the NE region (Figure 1). Different concentrations of oil were utilized to cover the maximum possible number of formulations from the NE region as listed in Table 2. Depending upon the phase diagram, the oil concentration could be raised up to $20 \%$ without any significant change in particle size to determine drug loading capacity and other characterization parameters. The particle size may increase upon further increase in oil contents. ${ }^{28}$ According to other criteria, the oil concentration should be such that it can completely solubilize the single dose of drug. According to the literature, the selection of non-ionic surfactants in low concentrations was considered quite suitable for effective drug delivery without causing irritation. ${ }^{29}$ For each NE formula, optimum concentration of $\mathrm{S} / \mathrm{Co}-\mathrm{S}$ mixture was selected for each percentage of selected oil. For the incorporation of DIF in the selected oil, $1 \%$ drug was considered as the required dose for incorporation.

\section{Evaluation of DIF/(DIF-IC)-Loaded Formulations Visual Inspection}

All the formulae (blank, DIF and DIF-IC loaded) were quite stable physically with no sign of color change, precipitation and phase separation (Figure 2). 


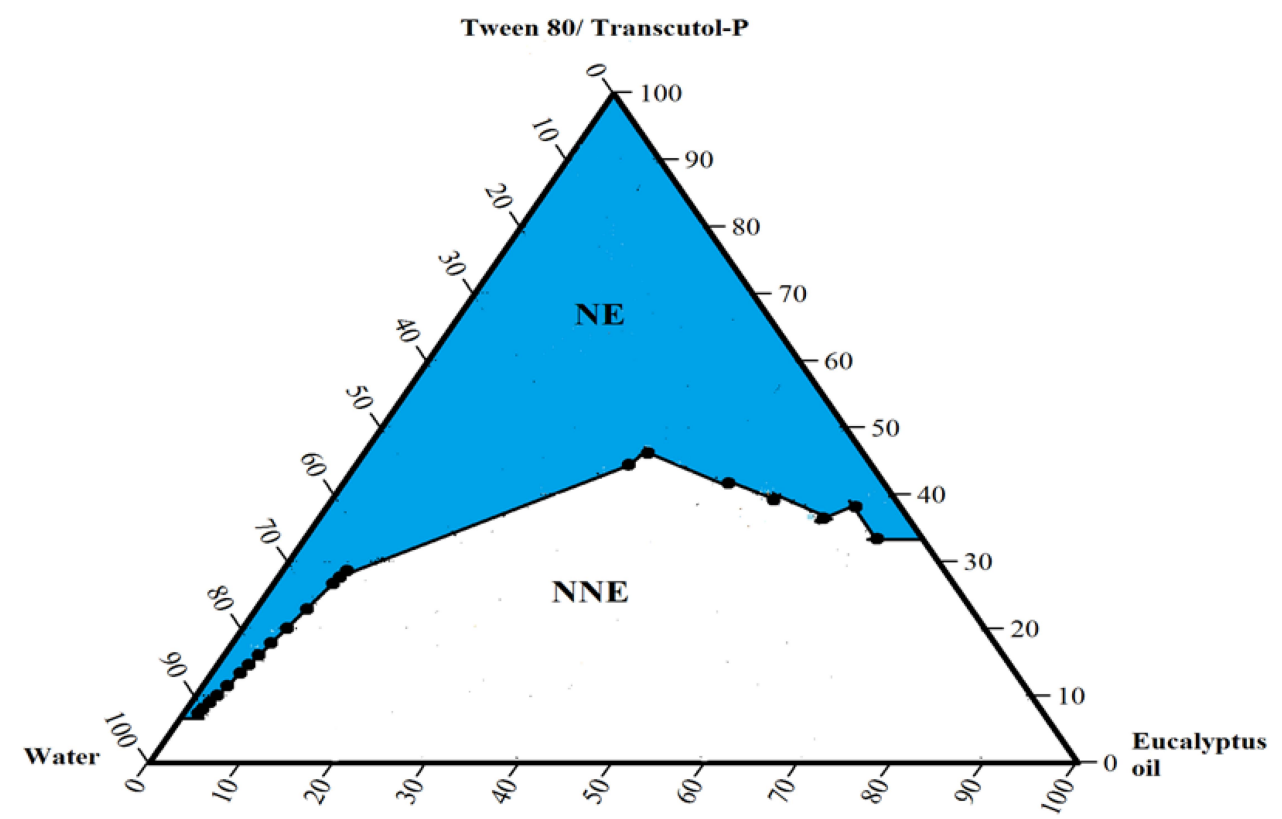

Figure I Pseudo-ternary phase diagram indicating nanoemulsion area with Eucalyptus oil, Tween 80/Transcutol-P $(\mathrm{S} / \mathrm{Cos})(\mathrm{I}: 2)$ and water. NE $=$ nanoemulsion region, NNE= non-nanoemulsion region.

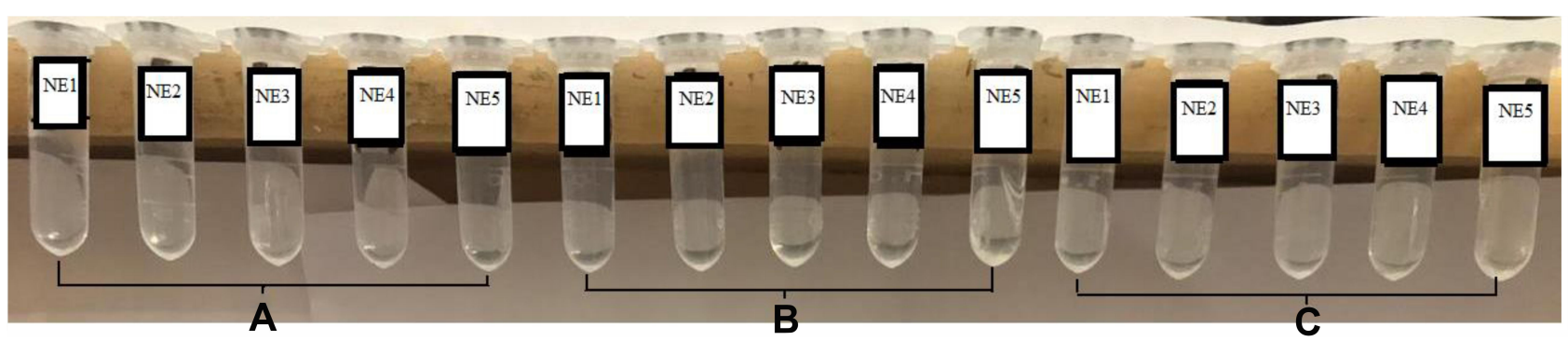

Figure 2 Physical appearance of (A) Blank, (B) DIF loaded and (C) solubility enhanced DIF (DIF-IC)-loaded nanoemulsion formulations.

Droplet Size and Polydispersity Index Measurement The droplet size of blank, and drug-loaded (DIF- and DIF-IC-loaded) NE are given in Table 3. The observed droplet size for NE 1, NE 2 and NE 3 formulations (blank, DIF and DIF-IC loaded) ranged from 14.36 to $85.46 \mathrm{~nm}$, whereas NE 4 and NE 5 showed diameter between $100-200 \mathrm{~nm}$.

\section{Measurement of Zeta Potential}

The zeta potential values varied from -10.70 to $-20.80 \mathrm{mV}$ for blank NE, -3.44 to $-13.46 \mathrm{mV}$ for DIF-loaded NE and -6.01 to $-13.76 \mathrm{mV}$ for DIF-IC-loaded NE formulations (Table 4). The negatively charged droplets experienced electrostatic repulsion among them which could lead to well separated and coalescence free NE formulae. ${ }^{30}$

Table 3 Results of Particle Size and Polydispersity Index of Blank, DIF- and DIF-IC-Loaded NE Formulations. Mean \pm SD, N = 3

\begin{tabular}{|l|l|l|l|l|l|l|}
\hline \multirow{2}{*}{ Formulations } & \multicolumn{2}{l}{ Particle Size (nm) } & \multicolumn{2}{l|}{ Polydispersity Index (PDI) } \\
\cline { 2 - 7 } & Blank & DIF Loaded & DIF-IC Loaded & Blank & DIF Loaded & DIF-IC Loaded \\
\hline NE I & $14.36 \pm 0.10$ & $17.33 \pm 0.006$ & $20.13 \pm 0.02$ & $0.08 \pm 0.00 \mathrm{I}$ & $0.12 \pm 0.00 \mathrm{I}$ & $0.09 \pm 0.005$ \\
NE 2 & $19.93 \pm 0.02$ & $23.03 \pm 0.02$ & $20.86 \pm 1.00$ & $0.06 \pm 0.00 \mathrm{I}$ & $0.06 \pm 0.005$ & $0.07 \pm 0.00 \mathrm{I}$ \\
NE 3 & $56.20 \pm 1.00$ & $72.40 \pm 0.70$ & $85.46 \pm 0.02$ & $0.20 \pm 0.00 \mathrm{I}$ & $0.06 \pm 0.00 \mathrm{I}$ & $0.06 \pm 0.00 \mathrm{I}$ \\
NE 4 & $130.33 \pm 0.00$ & $125.00 \pm 1.00$ & $185.00 \pm 1.00$ & $0.07 \pm 0.00 \mathrm{I}$ & $0.06 \pm 0.00 \mathrm{I}$ & $0.12 \pm 0.0 \mathrm{I}$ \\
NE 5 & $137.17 \pm 0.03$ & $111.00 \pm 0.50$ & $200.00 \pm 0.60$ & $0.09 \pm 0.00 \mathrm{I}$ & $0.07 \pm 0.00$ & $0.06 \pm 0.001$ \\
\hline
\end{tabular}


Table 4 Results of Zeta Potential of Blank, DIF and DIF-ICLoaded NE Formulations. Mean \pm SD, N = 3

\begin{tabular}{|l|l|l|l|}
\hline \multirow{2}{*}{ Formulation } & \multicolumn{2}{|l|}{ Zeta Potential (mV) } \\
\cline { 2 - 4 } & Blank & DIF Loaded & DIF-IC Loaded \\
\hline NE I & $-10.70 \pm 0.10$ & $-3.44 \pm 0.01$ & $-13.73 \pm 0.06$ \\
NE 2 & $-17.43 \pm 0.21$ & $-11.20 \pm 0.10$ & $-13.76 \pm 0.05$ \\
NE 3 & $-16.86 \pm 0.05$ & $-11.13 \pm 0.05$ & $-6.85 \pm 0.01$ \\
NE 4 & $-16.60 \pm 0.10$ & $-13.46 \pm 0.15$ & $-6.01 \pm 0.05$ \\
NE 5 & $-20.80 \pm 0.10$ & $-8.12 \pm 0.01$ & $-10.86 \pm 0.05$ \\
\hline
\end{tabular}

\section{$\mathrm{pH}$ and Conductivity Measurements}

The $\mathrm{pH}$ value of blank NEs ranged from 4.6-5.7, whereas in the case of DIF and DIF-IC-loaded NE, the observed $\mathrm{pH}$ was 3.58-4.05 thus ensuring acidic drug nature. Among all NE formulations, the results of $\mathrm{pH}$ were quite significant $(\mathrm{p}<0.05)$. The $\mathrm{pH}$ results of $\mathrm{NE}$ were divided into five distinct subgroups for blank, four subgroups for DIF-loaded NE formulations and three subsets for DIF-IC-loaded NE formulations according to Tukey-HSD tests. The values of conductivity varied between 26.65-72.34 $\mu \mathrm{s} / \mathrm{cm}$ for blank NE formulations and DIF-loaded NEs expressed conductivity values between $28.03-112.33 \mu \mathrm{s} / \mathrm{cm}$. The DIF-IC-loaded NEs showed conductivity value between 26.67 and 119.00 $\mu \mathrm{s} / \mathrm{cm}$. Conductivity values were found to be directly related with the amount of water in the system. ${ }^{31}$ For conductivity results among all NE formulations, there is a significant statistical difference $(p<0.05)$. According to post-hoc Tukey-HSD tests, the conductivity results of blank, DIF-loaded and DIF-IC-loaded NE formulations were categorized into five distinct subsets. The $\mathrm{pH}$ and conductivity values of blank and drug-loaded formulations are listed in Table 5.

\section{Determination of Viscosity}

The viscosity results of blank and drug-loaded preparations are listed in Table 6. All formulations (including
Table 6 Results of Viscosity of Blank, DIF-Loaded and DIF-ICLoaded NE Formulations. Mean \pm SD, $N=3$

\begin{tabular}{|l|l|l|l|}
\hline \multirow{2}{*}{ Formulation } & \multicolumn{2}{|l|}{ Viscosity (cP) } \\
\cline { 2 - 4 } & Blank & DIF Loaded & DIF-IC Loaded \\
\hline NE I & $16.77 \pm 0.11$ & $14.20 \pm 1.00$ & $13.80 \pm 0.10$ \\
NE 2 & $18.01 \pm 0.03$ & $19.73 \pm 0.60$ & $19.00 \pm 1.00$ \\
NE 3 & $20.06 \pm 0.02$ & $23.95 \pm 0.58$ & $25.00 \pm 2.00$ \\
NE 4 & $28.00 \pm 1.00$ & $27.97 \pm 0.03$ & $33.50 \pm 1.00$ \\
NE 5 & $30.40 \pm 1.00$ & $29.40 \pm 1.00$ & $34.80 \pm 0.10$ \\
\hline
\end{tabular}

blank and drug loaded) appeared to be less viscous, which is a characteristic hallmark of NE demonstrating Newtonian type flow pattern. ${ }^{32}$ According to Tukey -HSD tests, the viscosity results of all NE formulations (blank NE, DIF-loaded and DIF-IC-loaded NE formulations) were divided into four distinct subsets. Drug-loaded NEs expressed higher viscosity than the blank NE formulae.

The $\mathrm{pH}$ values for all nanoemulgel formulations ranged from 5.63-6.42 (Table 7). The $\mathrm{pH}$, viscosity and conductivity values of all nanoemulgel formulations generated statistically significant results $(\mathrm{p}<0.05)$.

\section{In vitro Skin Permeation Study}

Skin permeation involves drug release from carrier and ultimately absorbing into the skin which is why in vitro skin permeation is considered quite pivotal to predict in vivo permeation. ${ }^{33}$ The in vitro study of NEs was performed through Franz diffusion cells. Figure 3 (A and $\mathrm{B}$ ) illustrated the release profile of both DIF and DIF-IC-loaded NE. In the case of DIF-loaded NE formulations, NE 1 and NE 2 expressed higher release than other formulations, which could be explained on the basis of their relatively smaller size and low viscosity. Both NE 1 and NE 2 showed a similar release pattern up to 5 hours, after which a clear difference could be seen. NE 5 showed the lowest drug release among all NE-based formulae.

Table 5 Results of $\mathrm{pH}$ and Conductivity of Blank, DIF and DIF-IC-Loaded NE Formulations. Mean \pm SD, N = 3

\begin{tabular}{|l|l|l|l|l|l|l|}
\hline \multirow{2}{*}{ Formulations } & \multicolumn{2}{|l}{ pH } & \multicolumn{3}{l|}{ Conductivity $(\boldsymbol{\mu S} / \mathbf{c m})$} \\
\cline { 2 - 7 } & Blank & DIF Loaded & DIF-IC Loaded & Blank & DIF Loaded & DIF-IC Loaded \\
\hline NE I & $4.60 \pm 0.01$ & $3.58 \pm 0.01$ & $3.58 \pm 0.01$ & $72.34 \pm 0.02$ & $112.33 \pm 0.02$ & $119.00 \pm 1.00$ \\
NE 2 & $4.81 \pm 0.02$ & $3.76 \pm 0.01$ & $3.76 \pm 0.01$ & $56.00 \pm 1.00$ & $76.66 \pm 1.00$ & $72.33 \pm 1.00$ \\
NE 3 & $5.02 \pm 0.02$ & $3.78 \pm 0.02$ & $3.79 \pm 0.01$ & $49.00 \pm 0.5$ & $60.36 \pm 0.06$ & $63.03 \pm 0.50$ \\
NE 4 & $5.33 \pm 0.02$ & $3.91 \pm 0.01$ & $4.03 \pm 0.06$ & $38.00 \pm 2.00$ & $44.01 \pm 0.99$ & $46.00 \pm 1.00$ \\
NE 5 & $5.70 \pm 0.05$ & $4.05 \pm 0.01$ & $4.05 \pm 0.01$ & $26.65 \pm 0.99$ & $28.03 \pm 0.50$ & $26.67 \pm 1.00$ \\
\hline
\end{tabular}


Table 7 Results of $\mathrm{pH}$, Conductivity and Viscosity of DIF and DIF-IC-Loaded Nanoemulgel Formulations. Mean \pm SD, N $=3$

\begin{tabular}{|c|c|c|c|c|c|c|}
\hline \multirow[t]{2}{*}{ Parameters } & \multicolumn{3}{|c|}{ DIF-Loaded Nanoemulgel } & \multicolumn{3}{|c|}{ DIF-IC-Loaded Nanoemulgel } \\
\hline & CMC-Na & Na-ALG & $\mathbf{X G}$ & CMC-Na & Na-ALG & $\mathbf{X G}$ \\
\hline $\mathrm{pH}$ & $6.14 \pm 0.02$ & $5.98 \pm 0.03$ & $5.63 \pm 0.05$ & $6.42 \pm 0.004$ & $5.83 \pm 0.04$ & $5.66 \pm 0.01$ \\
\hline Viscosity (cp) & $6268 \pm 1.20$ & $1740 \pm 0.60$ & $11,339 \pm 1.5$ & $6538 \pm 1.00$ & $2100 \pm 0.60$ & $12,058 \pm 0.60$ \\
\hline Conductivity $(\mu \mathrm{s} / \mathrm{cm})$ & $|72| \pm 1.20$ & $1702 \pm 1.50$ & $840 \pm 0.60$ & $165 \pm 1.73$ & $1374 \pm 0.60$ & $830 \pm 0.00$ \\
\hline
\end{tabular}

The same trend could be observed with DIF-IC but their flux and permeability constant values were greater than those of pure DIF-loaded NEs. According to Tables 8 and 9 , the permeation flux tends to increase with increase in aqueous content and decrease in $\mathrm{S} / \mathrm{Co}-\mathrm{S}$ mixture. The flux values among all $\mathrm{NE}$ formulations expressed a significant statistical difference $(\mathrm{p}<0.05)$. According to Tukey-HSD tests, the values of flux of NE preparations were divided into six distinct subsets for DIF-loaded NE formulations and DIF-IC-loaded NE formulations.
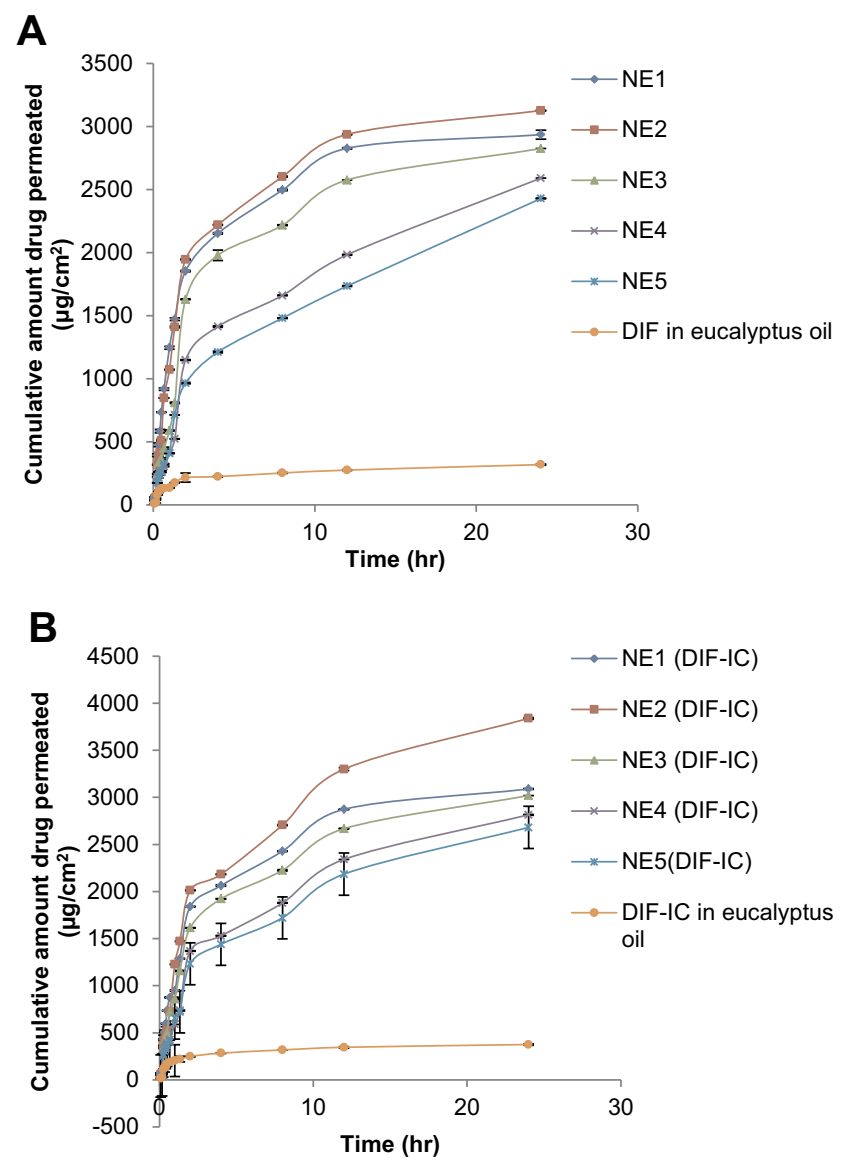

Figure 3 In vitro release profiles of DIF from nanoemulsion formulae with (A) DIF and (B) solubility enhanced DIF (DIF-IC) compared with that from oily drug suspension.
Figure 4 (A and B) illustrates in vitro release profiles of DIF- and DIF-IC-loaded nanoemulgel formulations using different gelling agents. A consistent rise in DIF in the receptor compartment was observed with time. In contrast to optimized NE formulation, NE-based gels showed a decrease in flux which could be better accredited to transformation to a highly organized nano/lamellar structure and increased viscosity.

It is presumed that by inclusion into the suitable colloidal carrier, intimate cutaneous contact could be maintained that will ultimately produce rapid onset of action. This finding was further supported by previous data. ${ }^{34}$ The results of permeation parameters for all nanoemulgel formulations are listed in Table 10.

The values of flux among all nanoemulgel preparations expressed significant statistical differences $(p<0.05)$.

Table 8 Permeation Flux and Permeability Constant of DIFBased NE Formulations

\begin{tabular}{|l|l|l|}
\hline Formulations & $\begin{array}{l}\text { Flux }(\mathbf{J}) \\
\left(\boldsymbol{\mu g} / \mathbf{c m}^{2} / \mathbf{h}\right)\end{array}$ & $\begin{array}{l}\text { Permeability Constant } \\
(\mathbf{K p})(\mathbf{c m} / \mathbf{h})\end{array}$ \\
\hline NE I & $53.57 \pm 1.00$ & 0.010 \\
NE 2 & $55.41 \pm 0.01$ & 0.011 \\
NE 3 & $50.18 \pm 0.02$ & 0.010 \\
NE 4 & $45.14 \pm 1.00$ & 0.009 \\
NE 5 & $42.26 \pm 0.01$ & 0.008 \\
DIF in eucalyptus oil & $3.49 \pm 0.00$ & 0.0003 \\
\hline
\end{tabular}

Table 9 Permeation Flux and Permeability Constant of DIF-ICBased NE Formulations

\begin{tabular}{|l|l|l|}
\hline Formulations & $\begin{array}{l}\text { Flux (J) } \\
\left(\boldsymbol{\mu g} / \mathbf{c m}^{2} / \mathbf{h}\right)\end{array}$ & $\begin{array}{l}\text { Permeability Constant } \\
(\mathbf{K p})(\mathbf{c m} / \mathbf{h})\end{array}$ \\
\hline NE I (IC) & $57.84 \pm 1.00$ & 0.011 \\
NE 2 (IC) & $73.98 \pm 1.00$ & 0.014 \\
NE 3 (IC) & $57.21 \pm 0.02$ & 0.011 \\
NE 4 (IC) & $55.02 \pm 1.00$ & 0.010 \\
NE 5 (IC) & $52.45 \pm 0.02$ & 0.010 \\
DIF-IC in eucalyptus oil & $5.31 \pm 0.00$ & 0.0005 \\
\hline
\end{tabular}



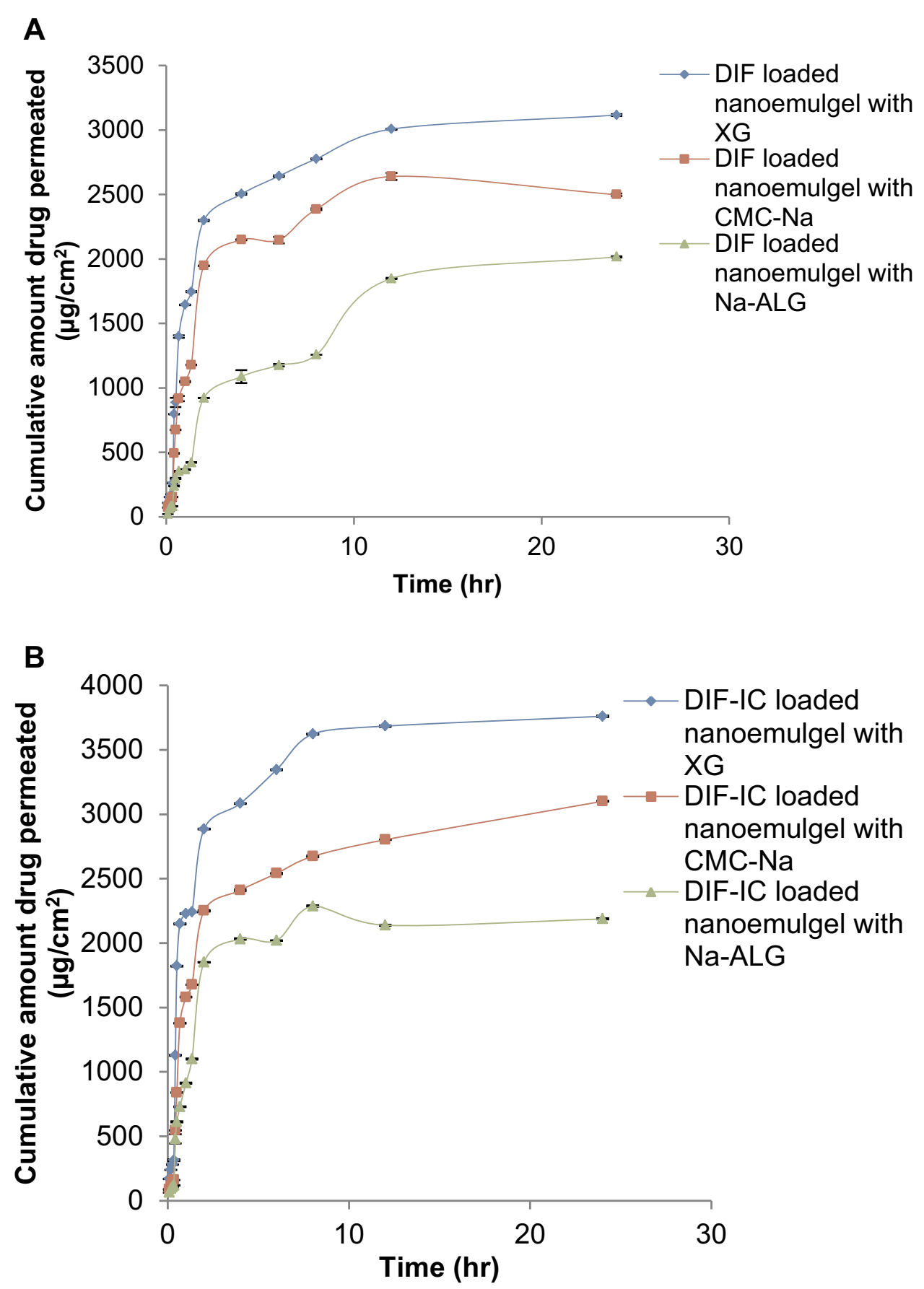

Figure 4 In vitro release profiles of DIF from nanoemulgel with (A) DIF and (B) solubility enhanced DIF (DIF-IC) by using different gelling agent.

According to Tukey-HSD tests, the values of flux of nanoemulgel preparations were divided into three distinct subsets for DIF-loaded nanoemulgel formulations and DIF-IC-loaded nanoemulgel formulations.

From the permeation study it was clear that XG-based nanoemulgel formulae having DIF-IC could be used as the most optimized formulation owing to its superb spreading properties, consistency, homogeneity and highest drug release even after 24 hours. Hence XGbased emulgel formulation could be used further for in vivo study.

\section{In vivo Study}

Table 11 (Figure 5) presents the results of the acute antiinflammatory models (carrageenan and histamine-induced paw edema model). On comparison, the inclusion 
Table 10 Permeability Parameters of Nanoemulgel Formulae

\begin{tabular}{|l|l|l|}
\hline $\begin{array}{l}\text { Nanoemulgel } \\
\text { Formulations }\end{array}$ & $\begin{array}{l}\text { Flux }(\mathbf{J}) \\
\left(\boldsymbol{\mu g} / \mathbf{c m}^{\mathbf{2}} / \mathbf{h}\right)\end{array}$ & $\begin{array}{l}\text { Permeability Constant } \\
(\mathbf{K p})(\mathbf{c m} / \mathbf{h})\end{array}$ \\
\hline DIF-XG & $44.64 \pm 0.002$ & 0.009 \\
DIF-CMC-Na & $37.33 \pm 0.0006$ & 0.007 \\
DIF-Na-ALG & $31.05 \pm 0.001$ & 0.001 \\
(DIF-IC) XG & $70.28 \pm 1.00$ & 0.014 \\
(DIF-IC) CMC-Na & $39.73 \pm 0.01$ & 0.008 \\
(DIF-IC) Na-ALG & $36.73 \pm 0.02$ & 0.007 \\
\hline
\end{tabular}

complex-based nanoemulgel (DIF-IC) showed statistically significant results.

Values shown are mean \pm SEM of three independent experiment $(\mathrm{N}=5)$. Where $*=\mathrm{p}<0.05, * *=\mathrm{p}<0.01, * * *$ $=\mathrm{p}<0.001$ and $\mathrm{ns}=\mathrm{p}>0.05$. Blue color shows comparison between DIF-loaded nanoemulgel $(10 \mathrm{mg} / \mathrm{mL})$ and diclofenac diethylamine emulgel (standard), green color shows comparison between DIF-loaded nanoemulgel $(10 \mathrm{mg} / \mathrm{mL})$ and DIF-IC-loaded nanoemulgel $(10 \mathrm{mg} / \mathrm{mL})$ and red color shows comparison between DIF-IC-loaded nanoemulgel (10 $\mathrm{mg} / \mathrm{mL}$ ) and diclofenac diethylamine emulgel (standard).

\section{Formalin-Induced Paw Edema Model}

Table 12 (Figure 6) presents the results of the chronic antiinflammatory models (formalin-induced paw edema model).

Values shown are mean \pm SEM of three independent experiment $(\mathrm{N}=5)$. Where $*=\mathrm{p}<0.05$, $* * *=\mathrm{p}<0.001$ and $\mathrm{ns}=\mathrm{p}>0.05$. Blue color shows comparison between DIF-loaded nanoemulgel $(10 \mathrm{mg} / \mathrm{mL})$ and diclofenac diethylamineemulgel (standard), green color shows comparison between DIF-loaded nanoemulgel $(10 \mathrm{mg} / \mathrm{mL})$ and DIFIC-loaded nanoemulgel $(10 \mathrm{mg} / \mathrm{mL})$ and red color shows comparison between DIF-IC-loaded nanoemulgel $(10 \mathrm{mg} /$ $\mathrm{mL}$ ) and diclofenac diethylamine emulgel (standard).

\section{Histopathological Studies}

Hematoxylin \& Eosin staining of tissue sections showed marked infiltration of tissues with inflammatory cells and pannus formation was observed in the untreated inflammation control group. In the diclofenac treated group mild dermal inflammation along with infiltration of inflammatory cells was observed. In the DIF treated group mild dermal hyperplasia with infiltration of inflammatory cells was observed while in the DIF-IC treated group a marked reduction in number of inflammatory cells infiltrating the tissues was observed. Tissue sections of the healthy group show normal architecture with no infiltration of inflammatory cells (Figure 7).

\section{Discussion}

\section{Solubility Study}

The basic components of nanoemulsion systems are oil/ surfactant/co-surfactant and active pharmaceutical moiety. The solubility of active moiety in individual component is decisive in determining the drug loading in final formulation. The surfactants and co-surfactants prevent coalescence in nanoemulsion formulation by providing a mechanical barrier and reduce the interfacial tension by adsorbing at the oil/water interface.

For the preparation of NE of DIF, the selected excipients were eucalyptus oil, Tween 80 (surfactant), Transcutol-P (cosurfactant) and Tween 80: Transcutol-P (1:2) ratio for subsequent work. DIF expressed the highest solubility in S/C0-S mixture (Tween $80+$ Transcutol-P) at the ratio of 1:2 (401.33 $\mathrm{mg} / \mathrm{mL}$ ). At 1:2 ratio, surfactant/co-surfactant mixture (tween 80: transcutol-P) displayed statistically significant results of DIF solubility compared with the other S/Co-S ratios.

\section{Development of a Pseudoternary Diagram}

The nanoemulsification efficiency is related directly to nanoemulsion field area. ${ }^{35,36}$ The process of nanoemulsification and of course nanoemulsion field area was influenced by the chain (hydrophobic) length of co-surfactant due to higher drug solubility in it. ${ }^{37}$ At low co-surfactant concentration, micelles formation is also reduced which ultimately leads to decreased solubilization capacity of the formed nanoemulsion. ${ }^{38}$

Table II Evaluation of Anti-Inflammatory Effect of DIF, DIF-IC-Loaded Nanoemulgel and Diclofenac Diethylamine Emulgels in Carrageenan and Histamine-Induced Paw Edema Model

\begin{tabular}{|l|l|l|l|l|l|l|}
\hline \multicolumn{2}{|l|}{ Carrageenan-Induced Paw Edema Model } & \multicolumn{2}{l|}{ Histamine-Induced Paw Edema Model } \\
\hline $\begin{array}{l}\text { Time } \\
\text { (Hours) }\end{array}$ & $\begin{array}{l}\text { DIF-Loaded } \\
\text { Nanoemulgel }\end{array}$ & $\begin{array}{l}\text { Diclofenac } \\
\text { Diethylamine Emulgel }\end{array}$ & $\begin{array}{l}\text { DIF-IC-Loaded } \\
\text { Nanoemulgel }\end{array}$ & \multicolumn{2}{l|}{$\begin{array}{l}\text { DIF } \\
\text { Nanoemulgel }\end{array}$} & $\begin{array}{l}\text { Diclofenac } \\
\text { Diethylamine Emulgel }\end{array}$ \\
\hline 1 & $14.30 \pm 0.47$ & $16.10 \pm 0.30^{*}$ & $27.40 \pm 0.42 * * * / * * *$ & $13.40 \pm 0.36$ & $15.70 \pm 0.33 * *$ \\
2 & $24.40 \pm 0.29$ & $24.90 \pm 0.47^{\text {ns }}$ & $40.40 \pm 0.25 * * * / * * *$ & $25.10 \pm 0.62$ & $25.00 \pm 0.42^{\text {ns }}$ & $28.10 \pm 0.33 * * * / * * *$ \\
3 & $36.40 \pm 0.42^{*}$ & $34.60 \pm 0.35$ & $59.90 \pm 0.36 * * * * * *$ & $35.40 \pm 0.50$ & $34.60 \pm 0.30^{\text {ns }}$ \\
\hline
\end{tabular}




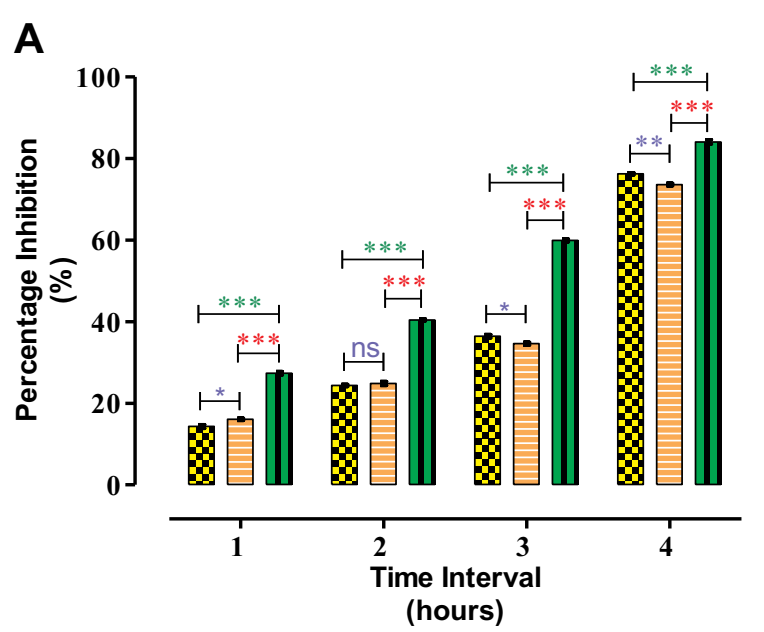

\author{
\$. DIF loaded nanoemulgel \\ $\boxminus$ Voltral $\circledast$ emulgel \\ III Solubility enhanced DIF (DIF-IC) \\ loaded nanoemulgel
}

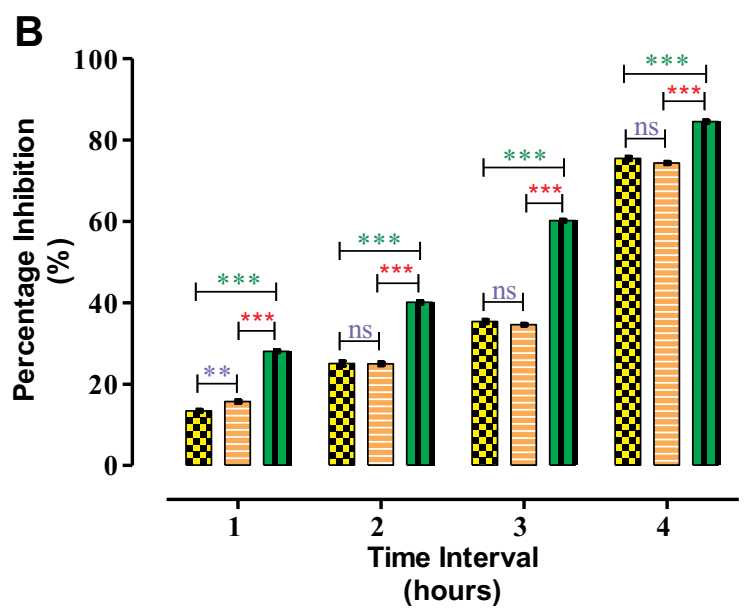

DIF loaded nanoemulgel

$\square$ Voltralß emulgel

W Solubility enhanced DIF (DIF-IC)

loaded nanoemulgel

Figure 5 Anti-inflammatory effect of DIF, DIF-IC-loaded nanoemulgel and Voltra ${ }^{\circledR}$ emulgels in carrageenan $(\mathbf{A})$ and histamine (B) induced paw edema model. Notes: Values shown are mean \pm SEM of three independent experiment $(N=5)$. Where $*=p<0.05, * *=p<0.01, * * *=p<0.001$ and ns $=p>0.05$. Blue color shows comparison between DIF-loaded nanoemulgel $(10 \mathrm{mg} / \mathrm{mL})$ and Voltral ${ }^{\circledR}$ emulgel (standard), green color shows comparison between DIF-loaded nanoemulgel $(10 \mathrm{mg} / \mathrm{mL})$ and DIF-IC-loaded nanoemulgel $(10 \mathrm{mg} / \mathrm{mL})$ and red color shows comparison between DIF-IC-loaded nanoemulgel $(10 \mathrm{mg} / \mathrm{mL})$ and Voltral ${ }^{\circledR}$ emulgel (standard).

So it was evident, that by increasing oil concentration, average droplet size also increased. The use of 15 and $20 \%$ of eucalyptus oil produced particle size greater than $100 \mathrm{~nm}$. Increased oil contents lead to NE droplets expansion which could be attributed to simultaneous reduction in $\mathrm{S} / \mathrm{Co}-\mathrm{S}$ proportion. ${ }^{39}$ Upon increasing the concentration of S/Co-S from 35 to 50\% (NE 1 -NE 5), there was an increase in mean droplet size. Surfactants cause interfacial film stabilization and condensation at high concentration, whereas addition of co-surfactant caused interfacial film expansion. ${ }^{40,41}$ The co-surfactants cause reduction in mean droplet size by penetrating into the surfactant film thereby reducing film viscosity and ultimately contribute to transparent formulation with lower curvature radius. ${ }^{17,42}$ So, optimum concentration of surfactant and co-surfactant was considered essential to produce a stable nanoemulsion.

\section{Droplet Size and Polydispersity Index Measurement}

All NE formulations (blank, DIF and DIF-IC loaded) were in the allowable size range of $20-200 \mathrm{~nm}^{43}$ Therefore all the formulations were considered to be acceptable in term of mean particle size. The mean particle size for blank, DIF and DIF-IC-loaded NE manifested statistically significant results $(\mathrm{p}<0.05)$. The mean particle size of NE preparations was categorized into five distinct subsets for blank and DIF-loaded $\mathrm{NE}$ and four subsets for DIF-IC-loaded NE formulations.

The homogeneity among the droplets could be assessed by measuring their polydispersity index (PDI) values and appeared to be inversely correlated to particles' homogeneity in the formulation. The PDI ranges from $0.0-1.0,{ }^{44}$ whereas the observed PDI for all 
Table 12 Evaluation of Anti-Inflammatory Effect of DIF, DIF-ICLoaded Nanoemulgel and Diclofenac Diethylamine Emulgels in Formalin-Induced Chronic Paw Edema Model

\begin{tabular}{|c|c|c|c|}
\hline Days & $\begin{array}{l}\text { DIF } \\
\text { Nanoemulgel }\end{array}$ & $\begin{array}{l}\text { Diclofenac Diethylamine } \\
\text { Emulgel }\end{array}$ & $\begin{array}{l}\text { DIF- } \\
\text { IC Nanoemulgel }\end{array}$ \\
\hline 1 & $1.36 \pm 0.05$ & $4.92 \pm 0.38 * * *$ & $9.37 \pm 0.25 * * * * * * *$ \\
\hline 2 & $6.80 \pm 0.32$ & $12.30 \pm 0.28^{* * * *}$ & $27.50 \pm 0.63 * * * / * * *$ \\
\hline 3 & $13.70 \pm 0.31$ & $18.80 \pm 0.40^{* * * *}$ & $40.00 \pm 0.21 * * * * * * *$ \\
\hline 4 & $42.90 \pm 0.54$ & $45.50 \pm 0.63^{*}$ & $61.00 \pm 0.51 * * * 1 * * * *$ \\
\hline 5 & $50.60 \pm 0.53$ & $51.00 \pm 0.64^{\mathrm{ns}}$ & $86.90 \pm 0.30^{* * * / * * * *}$ \\
\hline 6 & $65.10 \pm 0.57$ & $63.60 \pm 0.37^{\mathrm{ns}}$ & $87.30 \pm 0.33 * * * / * * * *$ \\
\hline 7 & $68.60 \pm 0.95$ & $83.30 \pm 0.34 * * *$ & $87.70 \pm 0.39 * * * / * * *$ \\
\hline 8 & $75.00 \pm 0.34$ & $84.00 \pm 0.48^{* * * *}$ & $88.20 \pm 0.25 * * * * * * *$ \\
\hline 9 & $75.10 \pm 0.35$ & $84.00 \pm 0.47^{* * * *}$ & $88.20 \pm 0.26 * * * * * * *$ \\
\hline 10 & $75.10 \pm 0.34$ & $84.00 \pm 0.47^{* * * *}$ & $88.30 \pm 0.27 * * * * * * *$ \\
\hline 11 & $75.10 \pm 0.34$ & $84.00 \pm 0.47^{* * * *}$ & $88.30 \pm 0.27 * * * / * * *$ \\
\hline 12 & $75.20 \pm 0.37$ & $84.00 \pm 0.47^{* * *}$ & $88.30 \pm 0.27 * * * / * * *$ \\
\hline 13 & $75.20 \pm 0.34$ & $84.00 \pm 0.49 * * *$ & $88.30 \pm 0.29 * * * / * * *$ \\
\hline
\end{tabular}

formulations was less than 0.5 thus ensuring uniform particle size distribution.

\section{Measurement of Zeta Potential}

The stability of NE (in accelerated study) is showed by their zeta $(\zeta)$ potential values. Particle size has influence on the value of zeta potential. The NE formulations should have higher values $( \pm 30 \mathrm{mV})$ of zeta potential in order to develop a stable and coalescence-free system. ${ }^{45}$ Nevertheless, zeta potential values are not appropriate for the estimation of $\mathrm{NE}$ stability, because the literature provides a broadrange of zeta potential values ranging from $1.5-45.5 \mathrm{mV}^{45,46}$

\section{Physicochemical Properties}

From the data, it was obvious that upon increasing oil, surfactant and co-surfactant mixture contents and water amount decreasing from $60-30 \%$, viscosity was increased significantly. This increase in viscosity could be better attributed to the rise in internal phase ratio in oil in water NE system.

The $\mathrm{pH}$ of final formulations was highly suggestive of their suitability for topical application without irritation. Normal adult skin $\mathrm{pH}$ is $5.5 .^{47}$ The nanoemulgel formulations exhibited higher viscosity than that of corresponding $\mathrm{NE}$ formulation so are quite suitable for topical application. $^{48}$

\section{In vitro Skin Permeation Study}

The release variation can be attributed to the viscosity. The higher the viscosity, the lower will be the drug release. ${ }^{49,50}$ The flux values were also higher for NE 1 and NE 2. This is further supported by previous literature that $\mathrm{o} / \mathrm{w}$ emulsions exhibited higher flux values than w/o emulsions ${ }^{51,52}$ (high aqueous content and lower surfactant level). This could possibly be explained by the thermodynamic property of the hydrophobic drug that becomes significant at lower surfactant levels thus ensuring higher drug release and penetration that ultimately enhanced the permeation flux. ${ }^{53,54}$

Variability in skin permeation profile could be better attributed to difference in compositions among all formulations. NE 1 and NE 2 of both DIF and DIF-IC produced higher drug release due to their lowest viscosity and

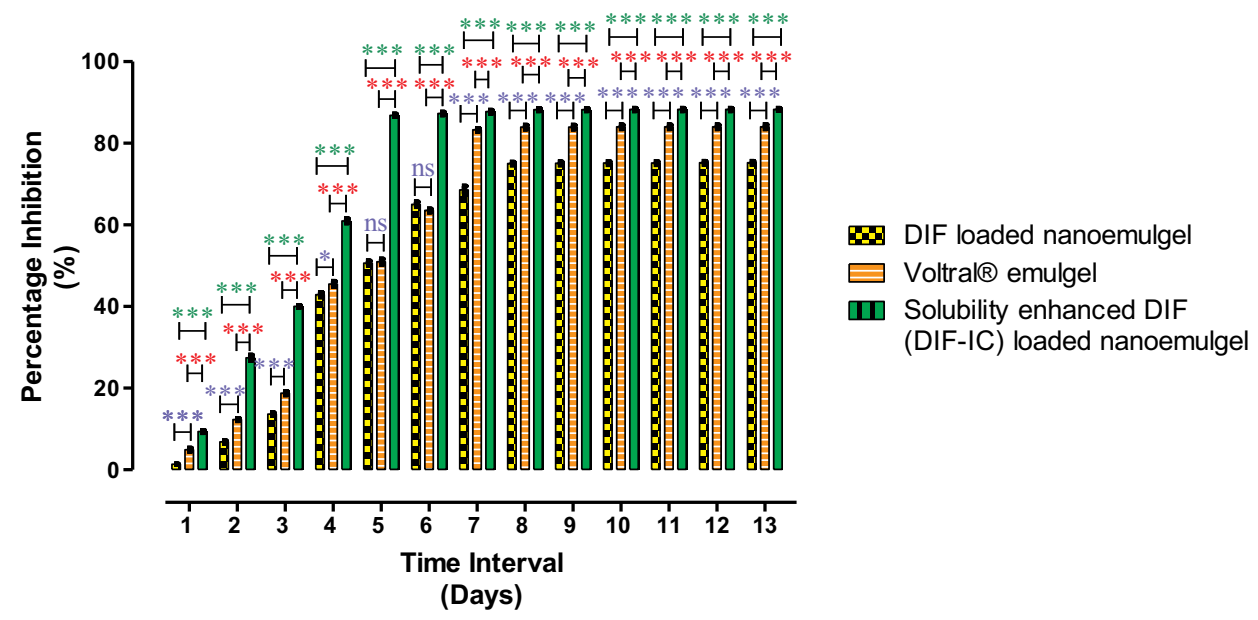

Figure 6 Anti-inflammatory effect of DIF, DIF-IC-loaded nanoemulgel and Voltral ${ }^{\circledR}$ emulgels in formalin-induced paw edema model.

Notes: Values shown are mean \pm SEM of three independent experiment $(N=5)$. Where $*=p<0.05, * * *=p<0.001$ and ns $=p>0.05$. Blue color shows comparison between DIF-loaded nanoemulgel $(10 \mathrm{mg} / \mathrm{mL})$ and Voltral ${ }^{\circledR}$ emulgel (standard), green color shows comparison between DIF-loaded nanoemulgel $(10 \mathrm{mg} / \mathrm{mL})$ and DIF-ICloaded nanoemulgel $(10 \mathrm{mg} / \mathrm{mL})$ and red color shows comparison between DIF-IC-loaded nanoemulgel $(10 \mathrm{mg} / \mathrm{mL})$ and $\mathrm{Voltral}{ }^{\circledR}$ emulgel $($ standard $)$. 

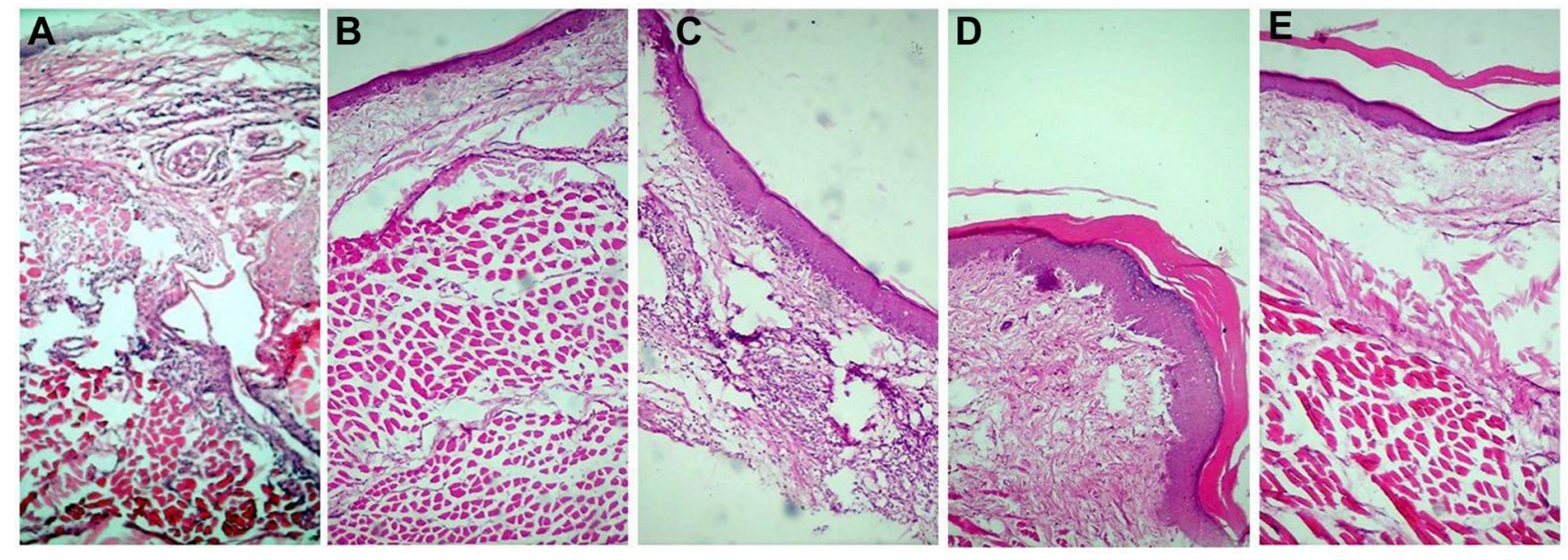

Figure 7 Histopathological studies of rats' paws using H\&E stains.

Notes: Where A is the untreated inflammation control group, B is the Voltral ${ }^{\circledR}$ emulgel treated group, C is the DIF-loaded nanoemulgel $(I 0 \mathrm{mg} / \mathrm{mL}), \mathrm{D}$ is the DIF-IC-loaded nanoemulgel $(10 \mathrm{mg} / \mathrm{mL})$ and $\mathrm{E}$ is the normal healthy control group. Marked reduction in number of inflammatory cells was observed in DIF-IC-loaded nanoemulgel ( $10 \mathrm{mg} /$ $\mathrm{mL}$ ) and Voltral ${ }^{\circledR}$ emulgel treated groups compared with untreated inflammation control group.

nanosized formulation droplets. Smaller sized droplets (having larger surface area) manifest more interfacial area for dissolution. ${ }^{55}$ In term of particle size, viscosity, conductivity and in vitro permeation, NE 2 formulation of both DIF and DIF-IC was quite suitable, so could be effectively used in a subsequent study to form emulgel formulations by using different gelling agents.

The nanosized droplets maintain closer cutaneous contact thus offering greater surface area for drug penetration hence ensuring higher drug content at the target site. ${ }^{56,57}$ Additionally, corneocytes in the stratum corneum swell due to the aqueous phase of NE thus facilitating higher diffusivity of hydrophobic drug through the formed channels. Hydration of corneocytes also causes disorientation of the lipid bilayer. ${ }^{28}$ Skin barrier function could be overcome by incorporation of penetration enhancers that cause fluidization of lipids present in the stratum corneum. Many of the common constituents of NEs are chemical penetration enhancers (Transcutol-P), so improved skin penetration of NE formulations could be better attributed to the altered barrier function of stratum corneum. ${ }^{58}$ The thermodynamic activity of drug (DIF) in the formulation is considered a consequential driving force for the release and cutaneous penetration of drug. ${ }^{14}$

The results of the release study illustrated that the permeability parameters of nanoemulgel formulations of both pure DIF and DIF-IC prepared with XG were considerably higher than $\mathrm{CMC}-\mathrm{Na}$ and Na-ALG. This was highly suggestive of suitability of $\mathrm{XG}$ as a good gelling agent for the preparation of DIF nanoemulgel. XG-based nanoemulgel of pure DIF expressed 1.19- and 1.43-fold higher flux compared with nanoemulgel prepared with $\mathrm{Na}-$ CMC and Na-ALG, respectively. Whereas DIF-IC-loaded nanoemulgel of $X G$ showed further increase in flux i.e. 1.76- and 2.00-fold increase in comparison with nanoemulgel prepared with $\mathrm{Na}-\mathrm{CMC}$ and $\mathrm{Na}-\mathrm{ALG}$, respectively. This provides evidence that the composition of NE formulae governs the permeability parameters of the drug. The permeation process is independent of concentration gradient as all nanoemulgel formulations have an equal drug load. DIF-IC-loaded nanoemulgel showed increased permeation which could possibly be justified as cyclodextrins liberate drug molecules from the inclusion complex thus maintaining higher proportion of free drug which ultimately lead to higher flux values. Although all the nanoemulgel formulations displayed significant results, XG manifested a superior drug release profile than the other two gelling agents.

\section{In vivo Study}

Edema induced by carrageenan is reproducible and classically involves two phases characterizing histamine and serotonin release (phase-I) along with prostaglandins secretions (phase-II). Carrageenan or histamine-induced edema lacks systemic effects and glucocorticoids or prostaglandins antagonists are the mainstay of therapy. ${ }^{59}$ Formaldehyde and Complete Freund's Adjuvant (CFA)induced edema in rats is an accurate model for estimation of anti-inflammatory effects of test drugs in chronic inflammation because of their pathological resemblance with human arthritis. The results of this study revealed that the anti-inflammatory action of DIF-IC-based 
nanoemulgel in the paw edema models of rats was notably supplemented by topical applications of NSAIDs. In our study, paw edema volume was considerably reduced after topical application of DIF-IC-based nanoemulgel compared with pure DIF containing nanoemulgel and diclofenac diethylamine in the same experimental prototype. The pharmacological activity of topical IC-based DIF nanoemulgel may be partly assigned to its enhanced permeability and solubility due to inclusion complexation. HP $\beta C D$ used in inclusion complexation improved cutaneous permeation by interacting with the stratum corneum of rat skin, so acts as a penetration enhancer. ${ }^{60}$

The incorporation of DIF-IC in the nanoemulgel formulation corroborated a higher degree of retention of therapeutic moiety and can offer a means for modifying the anti-inflammatory effect by substantially expanding the release period relative to pure DIF-based nanoemulgel and a commercially available emulgel (diclofenac diethylamine). Even the inflammatory activity was maintained up to the last analyzed time point with inclusion complex (DIF-IC)-based nanoemulgel. The results were consistent with previous literature that demonstrated enhanced anti-inflammatory activity of piroxicam by complexing with $\beta$-cyclodextrin. ${ }^{61}$ The inclusion complexes are highly available to targeted tissues, thus showing higher anti-inflammatory activity as compared with pure drug.

Specifically based on higher anti-inflammatory activity attained by the application of IC-based DIF nanoemulgel, one can recommend potential reduction in the DIF dose in the future work which may be applicable to attain the required therapeutic outcome without gastric insult such as ulceration and hemorrhage. Due to comparable efficacy of DIF-IC-based nanoemulgel with other nanoemulgel formulations, it could be a suitable choice for the treatment of inflammatory pain and hence can be a promising substitute to oral drug delivery.

\section{Conclusion}

In the present study, nanoemulsion formulations having composition of eucalyptus oil (oil phase), Tween 80 (surfactant) and Transcutol-P (co-surfactant) were prepared and characterized successfully. Surfactant and co-surfactant were used in ratio of 1:2 to examine particle size, in vitro release and physicochemical properties of DIF and DIF-IC.

The in vitro release was affected significantly by incorporation of DIF-IC. Being more soluble than pure DIF, a small portion of DIF-IC is settled at oil/water interface of $\mathrm{NE}$ and leads to slight increase in drug bioavailability.

The NE formulation (NE 2) of both DIF and DIF-IC was selected for the preparation of nanoemulgel formulations by using three different gelling agents, namely CMC-Na, NaALG and XG. XG-based nanoemulgel formulations exhibited optimum physical properties and in vitro release. However, the XG-based emulgel prepared with DIF-IC expressed the highest release profile and flux. Therefore XG-based nanoemulgel formulations of both DIF and DIF-IC were selected for in vivo study.

Three different models, viz. carrageenan-induced paw edema, histamine-induced paw edema and formalininduced paw edema models were applied to evaluate the anti-inflammatory effect of nanoemulgel formulations. The results illustrated that DIF-IC-loaded nanoemulgel prepared with XG ensured a modulated anti-inflammatory effect by maintaining a higher degree of retention of drug thus providing a prolonged effect compared with DIF-loaded nanoemulgel and a marketed diclofenac diethylamine emulgel.

In conclusion, a nanoemulgel delivery system offers many propitious and practical features for topical delivery of DIF and DIF-IC produce a localized anti-inflammatory effect. For the topical delivery of hydrophobic drugs, nanoemulgel formulations could be an attractive approach compared with other conventional topical formulations.

\section{Acknowledgments}

The authors wish to thank the Higher Education Commission (HEC), Pakistan for the grant no. 41771915-2MD4-010 (50039076).

\section{Funding}

This study was sponsored by Higher Education Commission (HEC), Pakistan grant no. 417-719152MD4-010 (50039076).

\section{Disclosure}

The authors report that they have no conflicts of interest for this work.

\section{References}

1. Kumar V, Al-Abbasi FA, Ahmed D, et al. Paederia foetida Linn. inhibits adjuvant induced arthritis by suppression of PGE 2 and COX-2 expression via nuclear factor-kB. Food Funct. 2015;6 (5):1652-1666. doi:10.1039/C5FO00178A

2. Firestein GS. Evolving concepts of rheumatoid arthritis. Nature. 2003;423:356-361.

3. Rabiei M, Kashanian S, Samavati SS, et al. Nanotechnology application in drug delivery to Osteoarthritis (OA), Rheumatoid arthritis (RA), and Osteoporosis (OSP). J Drug Deliv Sci Tech. 2020;102011. 
4. Furst DE, Emery P. Rheumatoid arthritis pathophysiology: update on emerging cytokine and cytokine-associated cell targets. Rheumatology. 2014;53:1560-1569.

5. Rabiei M, Kashanian S, Samavati SS, et al. Nanomaterial and advanced technologies in transdermal drug delivery. J Drug Target. 2020;28:356-367.

6. Hascicek C, Bediz-Ölçer A, Gönül N. Preparation and evaluation of different gel formulations for transdermal delivery of meloxicam. Turk J Pharm Sci. 2009;6:177-186.

7. Khullar R, Saini S, Seth N, et al. Emulgels: a surrogate approach for topically used hydrophobic drugs. Int J Pharm Bio Sci. 2011;1:117-128.

8. Priya LB, Baskaran R, Padma VV. Phytonanoconjugates in oral medicine. Nanostruct Oral Med. 2017;639-668.

9. Ahmad J, Kohli K, Mir SR, et al. Self-emulsifying nano carriers for improved oral bioavailability of lipophilic drugs. Rev Adv Sci Eng. 2012;1:134-147.

10. Khurana S, Bedi PM, Jain NK. Preparation and evaluation of solid lipid nanoparticles based nanogel for dermal delivery of meloxicam. Chem Phys Lipids. 2013;175-176:65-72. doi:10.1016/j. chemphyslip.2013.07.010

11. Pund S, Pawar S, Gangurde S, et al. Transcutaneous delivery of leflunomide nanoemulgel: mechanistic investigation into physicomechanical characteristics, in vitro anti-psoriatic and anti-melanoma activity. Int $J$ Pharm. 2015;487(1-2):148-156. doi:10.1016/j. ijpharm.2015.04.015

12. Eid AM, et al. Preparation, characterization and anti-inflammatory activity of Swietenia macrophylla nanoemulgel. $J$ Nanomed Nanotechnol. 2014;5(02):1. doi:10.4172/2157-7439.1000190

13. Badger AM, Lee JC. Advances in antiarthritic therapeutics. Drug Discov Today. 1997;2:427-435.

14. Sallam MA, Motawaa AM, Mortada SM. A modern approach for controlled transdermal delivery of diflunisal: optimization and in viv o evaluation. Drug Dev Ind Pharm. 2013;39:600-610.

15. Bashir M, Syed HK, Asghar S, et al. Effect of Hydrophilic Polymers on Complexation Efficiency of Cyclodextrins in Enhancing Solubility and Release of Diflunisal. Polymers. 2020;12:1564.

16. Kaur A, Bhoop BS, Chhibber S, et al. Supramolecular nano-engineered lipidic carriers based on diflunisal-phospholipid complex for transdermal delivery: qbD based optimization, characterization and preclinical investigations for management of rheumatoid arthritis. Int J Pharm. 2017;533:206-224.

17. Elmataeeshy ME, Sokar MS, Bahey-El-Din M, et al. Enhanced transdermal permeability of Terbinafine through novel nanoemulgel formulation; Development, in vitro and in vivo characterization. Future J Pharm Sci. 2018;4:18-28.

18. Jadhav C, Kate V, Payghan SA. Investigation of effect of non-ionic surfactant on preparation of griseofulvin non-aqueous nanoemulsion. J Nanostruct Chem. 2015;5:107-113.

19. Rao M, Sukre G, Aghav S, et al. Optimization of metronidazole emulgel. J Pharm. 2013;2013.

20. Patel J, Patel A, Raval M, et al. Formulation and development of a self-nanoemulsifying drug delivery system of irbesartan. $J A d v$ Pharm Technol Res. 2011;2:9.

21. Kaur DA, Raina AP, Singh NI. Formulation and evaluation of carbopol 940 based glibenclamide transdermal gel. Int J Pharm Pharm Sci. 2014;6:434-440.

22. Asif M, Saadullah M, Yaseen HS, et al. Evaluation of in vivo antiinflammatory and anti-angiogenic attributes of methanolic extract of Launaea spinosa. Inflammopharmacology. 2020;14:1-6.

23. Saleem M, Asif M, Parveen A, et al. Investigation of in vivo antiinflammatory and anti-angiogenic attributes of coumarin-rich ethanolic extract of Melilotus indicus. Inflammopharmacology. 2020.

24. Patel J, Patel B, Banwait H, et al. Formulation and evaluation of topical aceclofenac gel using different gelling agent. Int J Drug Dev Res. 2011;3:156-164.
25. Chen C, Han D, Cai C, et al. An overview of liposome lyophilization and its future potential. J Control Release. 2010;142:299-311.

26. Nielsen FH. Magnesium deficiency and increased inflammation: current perspectives. $J$ Inflamm Res. 2018;11:25.

27. Choudhury H, Gorain B, Pandey M, et al. Recent update on nanoemulgel as topical drug delivery system. J Pharm Sci. 2017;106:1736-1751.

28. Yuan Y, Li SM, Mo FK, et al. Investigation of microemulsion system for transdermal delivery of meloxicam. Int J Pharm. 2006;321:117-123.

29. Shafiq-un-Nabi S, Shakeel F, Talegaonkar S, et al. Formulation development and optimization using nanoemulsion technique: a technical note. AAPS Pharmscitech. 2007;8(2):E12.

30. Badran MM, Taha EI, Tayel MM, et al. Ultra-fine self nanoemulsifying drug delivery system for transdermal delivery of meloxicam: dependency on the type of surfactants. J Mol Liq. 2014;190:16-22.

31. Fanun M. Formulation and characterization of microemulsions based on mixed nonionic surfactants and peppermint oil. $J$ Colloid Interface Sci. 2010;343:496-503.

32. Azeem A, Ahmad FJ, Khar RK, et al. Nanocarrier for the transdermal delivery of an antiparkinsonian drug. AAPS PharmSciTech. 2009;10:1093-1103.

33. Küchler S, Herrmann W, Panek-Minkin G, et al. SLN for topical application in skin diseases-Characterization of drug-carrier and carrier-target interactions. Int J Pharma. 2010;390:225-233.

34. Ali MS, Alam MS, Alam N, et al. Preparation, characterization and stability study of dutasteride loaded nanoemulsion for treatment of benign prostatic hypertrophy. Iran J Pharm Res. 2014;13:1125.

35. Elnaggar YS, El-Massik MA, Abdallah OY. Self-nanoemulsifying drug delivery systems of tamoxifen citrate: design and optimization. Int J Pharm. 2009;380:133-141.

36. Elsheikh MA, Elnaggar YS, Gohar EY, et al. Nanoemulsion liquid preconcentrates for raloxifene hydrochloride: optimization and in vivo appraisal. Int $J$ Nanomedicine. 2012;7:3787.

37. Sakloetsakun D, Dünnhaupt S, Barthelmes J, et al. Combining two technologies: multifunctional polymers and self-nanoemulsifying drug delivery system (SNEDDS) for oral insulin administration. Int J Biol Macromol. 2013;61:363-372.

38. Chime SA, Kenechukwu FC, Attama AA Nanoemulsions-advances in formulation, characterization and applications in drug delivery. chapter; 2014.

39. Jyothi BJ, Sreelakshmi K. Design and evaluation of self-nanoemulsifying drug delivery system of flutamide. J Young Pharm. 2011;3:4-8.

40. Kale NJ, Allen JLV. Studies on microemulsions using Brij 96 as surfactant and glycerin, ethylene glycol and propylene glycol as cosurfactants. Int J Pharm. 1989;57:87-93.

41. Fahmy UA, Ahmed OA, Hosny KM. Development and evaluation of avanafil self-nanoemulsifying drug delivery system with rapid onset of action and enhanced bioavailability. AAPS Pharmscitech. 2015;16:53-58.

42. Baker RC, Florence AT, Tadros TF, et al. Investigations into the formation and characterization of microemulsions. I. Phase diagrams of the ternary system water-sodium alkyl benzene sulfonate-hexanol and the quaternary system water-xylene-sodium alkyl benzene sulfonate - hexanol. J Colloid Interface Sci. 1984;100:311-331.

43. Asadinezhad S, Khodaiyan F, Salami M, et al. Effect of different parameters on orange oil nanoemulsion particle size: combination of low energy and high energy methods. J Food Meas Charact. 2019;13:2501-2509.

44. Avachat AM, Patel VG. Self nanoemulsifying drug delivery system of stabilized ellagic acid-phospholipid complex with improved dissolution and permeability. Saudi Pharm J. 2015;23:276-289.

45. Negussie AH, Miller JL, Reddy G, et al. Synthesis and in vitro evaluation of cyclic NGR peptide targeted thermally sensitive liposome. J Control Release. 2010;143:265-273.

46. Wissing SA, Kayser O, Müller RH. Solid lipid nanoparticles for parenteral drug delivery. Adv Drug Deliv Rev. 2004;56:1257-1272. 
47. Sabu KR, Basarkar GD. Formulation, development and in-vitro evaluation of terbinafine hydrochloride emulgel for topical fungal infection. Int J Pharm Sci Rev Res. 2013;21:168-1673.

48. Rao S, Barot T, Rajesh KS, et al. Formulation, optimization and evaluation of microemulsion based gel of butenafine hydrochloride for topical delivery by using simplex lattice mixture design. J Pharm Invest. 2016;46:1-2.

49. Lira AA, Sester EA, Carvalho AL, et al. Development of lapachol topical formulation: anti-inflammatory study of a selected formulation. AAPS Pharmscitech. 2008;9:163-168.

50. Abd-Allah FI, Dawaba HM, Ahmed AM. Development of a microemulsion-based formulation to improve the availability of poorly water-soluble drug. Drug Discov Ther. 2010;4:257-266.

51. Djordjevic L, Primorac M, Stupar M. In vitro release of diclofenac diethylamine from caprylocaproyl macrogolglycerides based microemulsions. Int J Pharm. 2005;296:73-79.

52. Podlogar F, Rogač MB, Gašperlin M. The effect of internal structure of selected water-Tween $40^{\circledR}$-Imwitor $308^{\circledR}$-IPM microemulsions on ketoprofene release. Int J Pharm. 2005;302:68-77.

53. Rhee YS, Choi JG, Park ES, et al. Transdermal delivery of ketoprofen using microemulsions. Int J Pharma. 2001;228:161-170.

54. Zhao X, Liu JP, Zhang X, et al. Enhancement of transdermal delivery of theophylline using microemulsion vehicle. Int $J$ Pharm. 2006;327:58-64
55. Mantena AD, Dontamsetti BR, Nerella A. Formulation, optimization and in vitro evaluation of rifampicin nanoemulsions. Int J Pharm Sci Drug Res. 2015;7:451-455.

56. Akhter S, Jain GK, Ahmad FJ, et al. Investigation of nanoemulsion system for transdermal delivery of domperidone: ex-vivo and in vivo studies. Curr Nanosci. 2008;4:381-390.

57. Syamala U. Development \& optimization of allyl amine antifungal nanoemulgel using 23 factorial design: for the treatment of tinea pedis. Eur Sci J. 2013;1.

58. Abd E, Namjoshi S, Mohammed YH, et al. Synergistic skin penetration enhancer and nanoemulsion formulations promote the human epidermal permeation of caffeine and naproxen. J Pharm Sci. 2016;105:212-220.

59. Patil KR, Mahajan UB, Unger BS, et al. Animal models of inflammation for screening of anti-inflammatory drugs: implications for the discovery and development of phytopharmaceuticals. Int J Mol Sci. 2019;20:4367.

60. Babu RJ, Pandit JK. Effect of cyclodextrins on the complexation and transdermal delivery of bupranolol through rat skin. Int $J$ Pharm. 2004;271:155-165.

61. Dalmora ME, Dalmora SL, Oliveira AG. Inclusion complex of piroxicam with $\beta$-cyclodextrin and incorporation in cationic microemulsion. In vitro drug release and in vivo topical anti-inflammatory effect. Int J Pharm. 2001;222:45-55.
International Journal of Nanomedicine

\section{Publish your work in this journal}

The International Journal of Nanomedicine is an international, peerreviewed journal focusing on the application of nanotechnology in diagnostics, therapeutics, and drug delivery systems throughout the biomedical field. This journal is indexed on PubMed Central, MedLine, CAS, SciSearch ${ }^{\mathbb{}}$, Current Contents ${ }^{\mathbb{R}} /$ Clinical Medicine, $^{2}$

\section{Dovepress}

Journal Citation Reports/Science Edition, EMBase, Scopus and the Elsevier Bibliographic databases. The manuscript management system is completely online and includes a very quick and fair peer-review system, which is all easy to use. Visit http://www.dovepress.com/ testimonials.php to read real quotes from published authors. 